\title{
Os primeiros laudos arbitrais no MERCOSUL em matéria ambiental")
}

\author{
Elaine Ramos da Silva ${ }^{(*)}$
}

\section{Introduçăo}

Há alguns anos a proteção ambiental vem ocupando espaço em foros ligados ao comércio internacional. Neste sentido, por exemplo, tem-se as discussões no âmbito da OMC, sobretudo a partir da Rodada de Doha, os estudos da OECD sobre os efeitos ambientais da economia globalizada, ou ainda a posição defendida pelo UNCTAD'. São temas correntes nesses foros os relacionados à competitividade no comércio internacional em razão da regulamentação ambiental da produção, aos efeitos no comércio internacional do padrão de qualidade de produtos vinculados ao meio ambiente, bem como à liberalização do comércio internacional de forma sustentável.

Compatibilizar livre comércio e proteção ambiental também é um dos objetivos de blocos de cooperação e integração regional, consolidados ou não². E o Mercosul não é exceção ${ }^{3}$. Em foros regionais, inclusive, esta compatibilização

\footnotetext{
(") Versăo atualizada e ampliada da palestra sobre o mesmo tema proferida no Seminário sobre Harmonização da legislação ambiental no Mercosul, Porto Alegre, 28 de novembro de 2002.

(") Mestre em Direito Alemão, Especialista em Direito Europeu e em Direito Internacional Privado, Doutora em Direito. Professora Universitaria.

${ }^{1}$ Consultar detalhes sobre a Agenda Doha no site http:/www.wto.org; sobre os estudos da OECD, consultar hitp://www oecd.org; detalhes sobre o UNCTAD/XI em http:/www. unctad.ord.

${ }^{2}$ Ver, por exemplo, a politica ambiental da União Européia, extremamente desenvolvida, em http:f leuropa eu.intpol/envilindex pt.htm; ver também o preâmbulo da Convenção de Estocolmo, que instituiu em 1960 a Associação Européla de Livre Comércio (European. Free Trade AssociationEFTA), no site http:/secretariat.efta.int; o preâmbulo do Tratado que instituiu o North American Free Trade Agreement - NAFTA, que ressalta, inclusive, como propósito, o reforço na elaboraçăo e aplicação de leis e regulamentos em matéria ambiental, conf. site htto:/www nafta-sec-alena.org; a politica ambiental da Comunidade Andina, em hittp://www comunidadandina.oraldesarrollo.asp; e as disposiçöes ambientais contidas na Terceira Minuta de Acordo para a instituição da Area de Livre Comérclo das Américas - ALCA, no site hito:/www ftaa-alca.org.

${ }^{3}$ Assim designa o preâmbulo do Tratado de Assunção que instituiu as bases para a constituição de um mercado comum entre Argentina, Brasil, Paragual e Uruguai: "Entendendo que este objetivo deve ser alcançado mediante o aproveitamento mais eficaz dos recursos disponiveis, a preservação do meio ambiente $(. . .)^{\prime \prime}$, ver integra no site oficial http://www. mercosur.org.uy. Ver também a evolução dos trabalhos do Sub-Grupo de Trabalho $n^{\circ} 6$ que se ocupa de questões ambientais em: http:/t www.mercosulgovidr (normativas).
} 
deveria ser até mesmo mais fácil, haja vista o número reduzido de Estados-membros (comparando com organismos de caráter mundial), a previsão de competências para a elaboração normativa e a presença - ainda que em diferentes níveis - de mecanismos para a harmonização de políticas específicas. E, por certo, uma interpretação uniforme dessas nomas e o desenvolvimento de princípios orientadores por meio de um tribunal supranacional, cono ocorre, por exemplo, na União Européia, contribuem para consolidar tal objetivo.

No ano de 2002, foram proferidos dois laudos arbitrais no seio do Mercosul, cuja tônica centra-se na concretização de um dos objetivos do Tratado de Assunção, qual seja, na livre circulação de mercadorias. A questão ambiental, no caso, também estava presente; todavia, sob a perspectiva ambientalista, poderiam esses laudos ser considerados lacunosos ou mesmo omissos. Daí surgem basicamente duas questóes: no Mercosul, teria a livre circulação de mercadorias primazia em relação à proteção ambiental? E quais seriam os limites entre uma medida meramente protecionista e a invocação legítima de proteção ambiental por parte de um Estado para bloquear o ingresso de mercadorias advindas de outro? Analisar os laudos arbitrais com este enfoque é o tema da presente contribuição.

\section{A) Livre circulação de mercadorias versus proteção ambiental?}

1) Os primeiros laudos arbitrais em matéria ambiental

Desde a instituição do sistema de solução de controvérsias do Mercosul pelo Protocolo de Brasília (1991), confirmado pelo Protocolo de Ouro Preto (1994) e aperfeiçoado pelo Protocolo de Olivos $(2002)^{4}$, foram até agora proferidos nove laudos arbitrais por tribunais ad hoc ${ }^{5}$. Os laudos em análise correspondem ao sexto e ao sétimo desta série.

a) Laudo proferido em 09 de janeiro de 2002 por Tribunal Arbitral ad hoc relativo à controvérsia entre Uruguai (autor) e Brasil (réu) sobre a proibição de importação de pneumáticos remoldados procedentes do Uruguai

(1) Residiu a controvérsia, em síntese, na proibição pelo Brasil da importação de pneus remoldados procedentes do Uruguai. Tal se deu com a edição, pelo Governo brasileiro, da Portaria da Secretaria de Comércio Exterior do Ministério do Desenvolvimento, Indústria e Comércio Exterior (SECEX) $\mathrm{n}^{\circ} 8$, de 25.09.2000, dispondo sobre a concessão de licença de importação de pneumáticos recauchutados e usados, seja para consumo, seja como matéria-prima. A importaçăo de pneus recauchutados, vale ressaltar, estava autorizada há mais de dez anos (classificados na Posição 4012.10 da Nomenclatura Comum do MERCOSUL). A

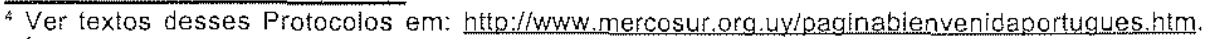
5 Integra dos laudos em: http://www, mercosul.oov.br/normativas/lista.asp.
} 
proibição residia na importação de pneus usados (classificado na Posição 4012.20). Sob o ponto de vista meramente técnico, a Posição 4012.10 designa pneus reformados, o que abrange pneus remoldados, recauchutados e recapados, todos distintos dos pneus usados. Com a Portaria, pretendia-se estender a proibição de importação dos pneus usados para as outras três categorias.

Uma empresa uruguaia, cuja principal atividade residia na reconstrução de pneumáticos para a exportação (para o Brasil), a partir da edição desta Portaria, teria de fechar suas portas, assim como quaisquer outras com este ramo de atividade.

Com a ediçâo da Portaria, houve a interrupção do fluxo comercial de pneumáticos importados do Uruguai pelo Brasil, especificamente dos pneus reformados ou recauchutados. A discussão que se instaurou diz respeito às diferenças técnicas e também ambientais entre pneus usados e reformados. A parte reclamante entendia que o Brasil emitira normas com o inequívoco intuito de impedir ou obstaculizar a importação de pneus reformados, violando as normas do MERCOSUL (artigos 1 do Tratado de Assunção, att. 1 do Anexo 1 e art. 10, inciso Il do mesmo Anexo), assim como princípios gerais de Direito Internacional Público, nomeadamente os princípios do pacta sunt servanda e da boa fé, bem como a vedação de venire contra factum proprium, dada a contradição na atuação normativa do Brasil.

A defesa brasileira, à parte de questões procedimentais, alega que os pneus recauchutados são inequivocamente bens usados, independentemente de haver sido objeto de algum processo industrial como intuito de restituir-lhe parte de suas características originais ou prolongar sua vida útil. Invoca, ainda, que a Portaria questionada visava corrigir falhas no sistema informatizado de comércio exterior do Brasil. Defende-se o Brasil, além disso, valendo-se do argumento de que a terminologia "usado" ou "recauchutado" é meramente comercial e não técnicocientífica, ocupando, inclusive, a mesma posição na Nomenclatura, com diferente Sub-posição).

(2) O laudo arbitral, quanto ao mérito propriamente dito, vale-se do marco normativo geral, do tratamento das restriçōes ao livre comércio, invocando o art. 1 do Tratado de Asunçăo, que dispöe acerca da livre circulação de bens, serviços e fatores de produção, por meio da eliminação de direitos aduaneiros e restrições não-tarifárias a circulação de mercadorias e de quaisquer outras medidas de efeito equivalente. Destaca o laudo, mais adiante, que a expressão "medidas de efeito equivalente" possui um caráter absoluto, não podendo ser empregada por um Estado, ainda que a medida não se destine a discriminação de produto estrangeito. Este tipo de norma é essencial a um sistema de integração regional, salienta o laudo.

No entendimento dos árbitros, em se tratando de "medidas de efeito equivalente", estas têm como conseqüência a imposição de barreiras e obstruções ao comércio entre os Estados litigantes, sendo incompatíveis com o livre comércio 
e a formação de um mercado comum. O laudo recorre, ainda, a princípios gerais, como o da proporcionalidade, da limitação à reserva da soberania, da razoabilidade e da previsibilidade comercial.

Argumentam os átbitros que havia efetivamente a proibição de importação de pneus usados, mas nunca de recauchutados, elencando uma série de pronunciamentos de órgăos brasileiros acetca da diferença entre esses dois tipos.

Acresce, por fim, o laudo que, em um processo de integração, independentemente do estágio em que se encontre, não podem variar as regras do jogo a qualquer momento. Neste sentido, considerou o laudo a Portaria da Secretaria de Comércio Exterior do Ministério de Desenvolvimento, Indústria e Comércio Exterior incompatível com a normativa do MERCOSUL, determinando que o Brasil adaptasse sua legislação interna.

b) Laudo proferido em 19 de abril de 2002 por Tribunal Arbitral ad hoc relativo às controvérsias entre Argentina (autora) e Brasil (réu) sobre os obstáculos ao ingresso de produtos fitossanitários argentinos no mercado brasileiro e a nãoincorporação de resoluçôes do Grupo Mercado Comum pelo Brasil

(1) O objeto da controvérsia do segundo laudo arbitral em análise foram os obstáculos ao ingresso de produtos fitossanitários argentinos no mercado brasileiro decorrentes da não-incoporação, pelo Brasil, de Resoluçoes do Grupo Mercado Comum, o que impediu sua vigência no MERCOSUL. Tais resoluçōes tratam da facilitação do comércio de produtos fitossanitários no MERCOSUL, sobretudo por meio do reconhecimento por parte dos Estados-membros do sistema de registros desses produtos em nível nacional

O Brasil alega que o art. 1 do Tratado de Assunção não veda a adoção de medidas unilaterais consideradas necessárias para determinados objetivos de política pública de proteção à saúde, ao meio ambiente e a segurança da população. Invoca, neste sentido, a exceção contida no art. 50 do Tratado de Montevideo de 1980 $(\mathrm{ALADI})^{?}$. Argumenta, ainda, no que diz respeito à obrigatoriedade ou náo de incorporação de medidas advindas de órgãos do MERCOSUL, que se trata de uma obrigação, porém sem prazo para cumprimento.

\footnotetext{
${ }^{5}$ Resoluções GMC 48/96, 87/96, 149/96, 156/96 e 71/98. Textos em http//wwww.mercosul.gov.br (normativas).

7 Dispõe o art. 50 do Tratado de Montevidéu: "Nenhuma disposição do presente Tratado será interpretada como impedimento à adoçäo e ao cumprimento de medidas destinadas à: a) Proteção da moral pública; b) Aplicação de leis e regulamentos de segurança; c) Regulação das importaçöes ou exportações de armas, munições e outros materiais de guerra e, em circunstâncias excepcionais, de todos os demais artigos militares; d) Proteção da vida e saúde das pessoas, dos animais e dos vegetais; e) importação e exportação de ouro e prata metálicos; f) Proteção do patrimônio nacionais de valor artístico, histórico ou arqueológico; e g) Exportaçăo, uțilizaçăo e consumo de materiais nucleares, prooutos radioativos ou qualquer outro material utilizável no desenvolvimento ou aproveitamento da energia nuclear."
} 
(2) O laudo entendeu, quanto à obrigação de internalização de Resoluções editadas em 1996 e 1998 acerca do comércio de produtos fitossanitários, com base em princípios de Direito Internacional Público, que já havia expirado o prazo razoável para tanto, restando, pois, caracterizada uma situação de incumprimento. Assim, determinou que o Brasil incorporasse as normas citadas em um prazo de 120 dias a contar da data notificaçăo do laudo.

Quanto à invocação da exceção do art. 50 do Tratado de Montevideo, o laudo entendeu que se tratava de uma invocaçăo genérica à saúde humana, animal ou vegetal e que, por isso, a omissão de incorporação de resoluções do Grupo constitui conceitualmente uma restrição não-tarifária à circulação de mercadorias.

2) A compatibilização dos objetivos

a) A livre circulação de mercadorias

Ao definir "mercado comum", enfatiza o Tratado de Assunção, em seu artigo $1^{\circ}$, tratar-se de um espaço onde reste assegurada a livre circulação de mercadorias, serviços e fatores produtivos, aqui compreendidos capital e trabalho ${ }^{8}$, dos quais resulta a liberdade de circulaçăo de capital c de trabalhadores e, como conseqüência, a liberdade de estabelecimento. Estas liberdades devem ser obtidas, entre outros, por meio da eliminação dos direitos alfandegários, restrições nãotarifárias à circulação do mercado e qualquer outra medida de efeito equivalente.

A despeito da fixação de objetivos claros já há mais de 13 anos, muito semelhantes, aliás, a um dos primeiros objetivos fixados no Tratado de Roma que estabeleceu a Comunidade Européia ${ }^{9}$, a prática no Mercosul demonstra que o ponto principal da integração buscada é ainda a livre circulação de mercadorias. E a experiência cinqüentenária daquela auxilia na elucidação de algumas questões aqui relevantes.

Mas o que significa esta liberdade?

A liberdade em análise importa na supressăo de todos os obstáculos para circulação de mercadorias entre os Estados-membros. No caso do Mercosul, esta supressão dá-se por meio da eliminação de direitos alfandegários ${ }^{10}$ e de restrições

\footnotetext{
Assim SILVA, Elaine Ramos da, Rechtsangleichung im MERCOSUL - Perspektiven für das Niederlassungsrech $\{$ von Geselischaften anhand von Erfahrungen in der Europäischen Union, Baden-Baden: NOMOS, 2002, p. $37 \mathrm{com}$ outras referências.

${ }^{9}$ Ver artigo $3^{\circ}$, alineas a) e c) do Tratado de Roma. Ver a respeito KRAEKEL, Der Abbau von Maßnahmen kontingentgleicher Wirkung als Instrument zur Marktöffnung: Europäische Gemeinschaften und MERCOSUR im Vergleich, München, 1997.

to Fala-se, neste sentido, em bareiras tarifárias, as quais referem-se aos direitos aduaneiros, ou seja, os tributos que o Estado faz incidir sobre as mercadorias que transpõem as fronteiras do território nacional, no ato de entrada ou de saida. Pode-se distinguir entre direitos aduaneiros de importação, que såo os mais comuns, incidindo sobre produtos originados dos paises-membros da zona de livre comércio, e direitos aduaneiros de exportação, cobrados sobre mercadorias que saem do território nacional, Ver RATTI, Bruno, Vade-mécum e Comércio Internacional e Câmbio, São Paulo: Aduaneiras, 1991.
} 
não-tarifárias à circulação de mercadorias e qualquer outra medida de efeito equivalente $^{11}$. Porém, para a concretização desta liberdade, não apenas se impóe a eliminação de barreiras, como também a vedação de criação de novos obstáculos ${ }^{12}$. Ressalte-se que qualquer enumeração que aqui se faça sobre barreiras não-tarifárias seria simplesmente exemplificativa. Isto se deve em virtude da prática cortente em outros processos de integração regional, nos quais a capacidade inventiva dos Estados-Membros, em nome da proteção dos produtos nacionais e em defesa do mercado nacional, é infindável ${ }^{13}$.

Vale, ainda, registrar que desfrutam da liberdade de circulação todos os produtos apreciáveis em dinheiro e passiveis de ser objeto de transaçoes comerciais, independentemente de sua natureza, de suas qualidades específicas, de sua utilização, de sua origem ${ }^{14}$. Nesta definição enquadram-se, por exemplo, produtos agrícolas, industriais, criaçóes literárias e artísticas, ou até mesmo energia (eletricidade, gás, etc.). Em uma decisão histórica, o Tribunal de Justiça das Comunidades Européias reconheceu como mercadoria, inclusive, lixo reciclado ou reciclável ${ }^{15}$.

Desde que vigente uma pauta aduaneira comum, beneficiam-se desta liberdade tanto os produtos originários dos Estados-membros como produtos provenientes de terceiros países, desde que regularmente importados.

Nos laudos sob análise tratava-se da livre circulação de pneumáticos remoldados advindos do Uruguai e de produtos fitossanitários atgentinos no mercado brasileiro, ambos objetos que se enquadram na definição de "mercadoria". O Brasil, no entender dos árbitros nos dois laudos, teria violado as disposiçóes acordadas no Tratado de Assunção por meio de uma ação e de uma omissão. A ação diz respeito à alteração de legislação, proibindo a importação de pneus remoldados do Uruguai, contrariando procedimento anterior; a omissão se deu pela não-incorporação de um norma emanada do Mercosul, inviabilizando o ingresso no país de produtos fitossanitarios advindos da Argentina. Ambas as medidas corresponderiam a barreiras näo-tarifárias ou medidas de efeito equivalente. Semelhantes violaçóes já ensejaram na Comunidade Européia o reconhecimento por parte do Tribunal de Justiça da responsabilidade por ação ou omissão legislativa

\footnotetext{
"Barreiras não-tarifárias corresponderiam àquelas medidas govennamentais, de caráter unilateral, que têm por efeito primordial a restrição das imporlações. Destacam-se aqui a fixação de cotas, a exigência de licença de importação, o controle de preços, enfim, quaisquuer medidas de caráter administrativo, cambial ou de qualquer natureza que impeçam ou dificultem o comércio reciproco. Conf. RATTI, op. cit. Sobre "medidas de efeito equivalente" ver FARIA, José Ângelo Estrella, $O$ Mercosul: Principios, Finalidade e Alcance do Tratado de Assunção, Brasilia: MRE/SGIE/NAT, 1993, p. 90 e segs.

12 Assim, por exemplo, a política da então Comunidade Econômica Européla, art. 12 do Tratado de Roma, na versão de 1957.

${ }^{13}$ Ver exemplos em SILVA, Elaine Ramos da, A Área de Livre Comércio das Américas (ALCA): relaçōes com outros tratados de integração regional e de comércio internaciona, in: Rev. Estudos Jurídicos, vol. $35, \pi^{\circ} 94,2002$, São Leopoldo: UNISINOS, p. 185-187.

if Assim define, por exemplo CAMPOS, João Mota de, Manual de Direito Comunitario, $3^{a}$. Ed., Lisboa: Fundação Calouste Gulbenkian, 2002, p. 514.

${ }^{15}$ Ac. de 9.7 .1992 (Comissão versus Bélgica), Proc, C-2/90, TJCE Col. 1992.
} 
de um Estado-membro e o conseqüente dever de indenizar o particular lesado, verificados determinados requisitos ${ }^{i 6}$.

A pergunta que dos laudos decorre: Teria a livre circulação de mercadorias primazia frente à proteção ambiental?

b) A proteção ambiental como limite à livre circulação de mercadorias

Os Anexos do Tratado de Assunção, como não poderia deixar de ser, prevêm algumas limitações à livre circulação de mercadorias, tais como a instituição de cláusulas de salvaguarda, bem como um regime de exceçóes, segundo o qual nenhuma disposição do Tratado deve ser interpretada como impedimento à adoção de medidas destinadas à proteção da moral pública, à aplicação de leis e regulamentos de segurança, à proteção da vida e saúde das pessoas, dos animats e dos vegetais, entre outros. Em verdade, não consta exatamente no Anexo do Tratado tal previsão, mas sim remissão ao art. 50 do Tratado de Montevidéu de 1980, supra mencionado. Exceção genérica semelhante a este dispositivo consta do art. 30 do Tratado de Roma, bem como dos artigos XX e XXI do GATT ${ }^{1 ?}$.

Com efeito, não se poderia priorizat os objetivos comerciais de um Tratado internacional em detrimento da saúde pública e da proteção de animais e vegetais. Mesmo porque é um dos princípios orientadores do Tratado de Assunção a proteção ambiental, conforme designa seu preâmbulo, ainda que tal năo se consubstancie nos dispositivos do próprio Tratado. Alás, também no Tratado de Roma, na versão original, inexistia base normativa acerca da proteção do meio ambiente; a evolução desta matéria, sobretudo a partir da década de 70 , resultou na concepção de uma política ambiental comunitátia. E esta política tem, inclusive, status especial en relação às demais, em razão da cláusula de interdependência ("Querschnittklausel"), segundo a qual a proteção ambiental deve ser observada na elaboração e concretização das demais políticas comunitárias ${ }^{18}$.

No Mercosul, há legislação ambiental - ainda que modesta - gerada a partir da estrutura institucional dessa organização internacional, adotadas principalmente pela necessidade de harmonizar as distintas legislaçóes ambientais dos Estadosmembros, bem como pela necessidade de coordenar determinadas políticas setoriais.

Dá resulta que a livre circulação de mercadorias não tem primazia sobre a proteção ambiental. Tratam-se de objetivos que devem ser perseguidos

\footnotetext{
16 Ac. de 19.11.1991 (Andrea Francovich e outros versus República Italiana). Proc. C-6/90 e C-9/90, TJCE Col. 1991, p. 1-5357 (responsabilidade por omissão do legislacor) e Ac. de 5.3.1996 (Brasserie du pêcheur versus República Federal da Alemanha e The Queen versus Secretary of State for Transport, ex parte Factortame), Proc. C-46/1993 e C-48/1993, TJCE Col. 1996, p. 1-1029 (responsabilidade por ato legislativo).

17 Ver comparação em FARIA, ob. cit,, p. 102 e segs.

t8 Sobre o tema OPPERMANN, Thomas, Europarecht, 2a . Aufl., Munique: C.H.Beck, p. 865-884.
} 
simultaneamente, de acordo com a vontade dos Estados-membros expressa nos instrumentos que embasam as relaçōes entre eles.

Não obstante, a invocação unilateral por parte de um Estado de proteção ambiental deve pautar-se em fatos concretos. Sua análise deve ser feita de forma individualizada, caso a caso. Do contrário, corre-se o risco de a medida tomada ser considerada protecionista.

\section{B) Proteção ambiental legítima versus protecionismo}

Em ambos os laudos arbitrais o Brasil invocou a previsäo do art. 50 do Tratado de Montevidéu de 1980 para obstaculizar o ingresso dos produtos pneus remoldados e produtos fitossanitários. Tratou-se o argumento de defesa de invocaçāo legítima à proteção ambiental ou de uma mera medida protecionista?

1) Legitimidade da proteção ao meio ambiente e à saúde humana

Desde a publicação dos laudos arbitrais em discussão não foram poucas as vozes contrárias às duas decisōes. Com efeito, não apenas dados técnicos concretos como também o bom senso demonstram uma ameaça ao meio ambiente brasileiro com a entrada no país dos produtos objetos das controvérsias.

No que tange aos pneus usados, em que pese a importação se mostrar um lucrativo negócio para alguns brasileiros, dados os baixos custos na aquisição - via importação - e os valores obtidos com a sua comercialização no mercado nacional ${ }^{19}$, é manifesta a agressão ambiental do produto. Em primeiro lugar por não se tratar de produto novo, mas de um bem com a vida útil prolongada ou prolongável e, neste sentido, mais curta que a daquele. A matéria-prima utilizada (borracha vulcanizada), por seu turno, não é degradável; sua queima é fator altamente poluente. A reciclagem desses pneus é de altíssimo custo. Além disso, a disposição incorreta de pneus usados acarreta mais um problema: torna-se-os criadouros de mosquitos da dengue. Em síntese: trata-se de um resíduo indesejáve ${ }^{20}$ ou, em expressão mais direta, de lixo ambiental ${ }^{21}$.

Segundo dados da Secretaria de Comércio Exterior (Secex) do Ministério do Desenvolvimento, Indústria e Comércio, desde 1990 entraran no país cerca de 38,1 milhóes de pneus usados, aumentando o passivo de cerca de 100 milhôes de unidades depositadas em locais inapropriados ${ }^{22}$. O Governo brasileiro, em

\footnotetext{
Ver Editorial do Estado de São Paulo de 19.03.2003. Por algum tempo várias liminares foram concedidas as importadores de pneus, permitindo a manutenção das importações.

20 Assim manifesta-se o relatório técnico realizado pela indústria automotiva brasileira e contido nos argumentos de defesa do Brasił no laudo em análise.

21 Expressão usada, por exemplo, no Editorial do site: http://www. recicláveis.com.br.

22 Ver dados no site do Ministério do Meio Ambiente (noticias de 20.11.2003), http:// www.mma.gov.br.
} 
cumprimento à determinação do laudo arbitral, editou Decreto liberando da cobrança de multa a importação de pneus usados provenientes dos países do Mercosul. Isto significa a eliminação da barteira imposta, que limitava a circulação. Conta-se, com isso, com o aumento das importaçóes, sobretudo advindas do Uruguaí e do Paraguai, segundo informações gerais da impressa. O problema certamente não se encerra aqui. O Brasil importa pneus usados de outros países, sobretudo europeus. Persistindo a imposição de multa para a importação de pneumáticos usados desses países, nada obsta que a importação se dê por meio de um parceiro do Mercosul, passando o produto a desfrutar do mesmo status do produto nacional e sendo, portanto, passivel de ser exportado novamente - agora sem limitaçóes -para o Brasil.

No tocante aos produtos fitossanitários, mais precisamente ao fato de um produto desta natureza poder obter registro em um Estado-membro e ser comercializado em outro, de acordo com as Resoluções emanadas do próprio Mercosul, é sabido que o Brasil possui uma das mais rigorosas legislações do mundo sobre condiçóes para registros desses produtos. O princípio da similaridade, admitido pelas Resoluçöes, possibilita abrir uma brecha para a circulação de certos produtos ditos "genéricos" no Brasil, a partir de seu registro em outro Estadomembro. A razão do rígido controle de produtos fitossanitários no Brasil se justifica pelo risco que esses produtos apresentam ao meio ambiente e à saúde humana. Aliado a isso, vale registrar que ainda não estão harmonizadas no âmbito do Mercosul as formas e as condições para a efetivação deste registro. Também não são harmônicas as legislaçoes ambientais dos quatro países-membros. Ou seja, introduzit no país uma legislação que possa ter (ou tenha efetivamente) como efeito a redução das medidas de segurança para a comercialização de produtos fitossanitários é pôr em risco a saúde pública. Com isso obtém-se certamente uma harmonização de legislações, porém levando em consideração parâmetros inferiores aos nacionais brasileiros.

Ainda que uma potencial deficiência ou insuficiência no controle e registro de produtos fitossanitários - a partir dos parâmetros brasileiros - por si só possa não ser considerada como fato concreto para legitimar a defesa brasileira no laudo em análise, é indubitável, por outro lado, a intenção da norma brasileira ao proibir a importação de pneus usados: proteger o meio ambiente e não o mercado nacional de pneus usados.

Não obstante, os argumentos apresentados como defesa pelo Brasil nos dois laudos não se sustentam por si só. No caso dos pneus usados, pecou o Brasil pela confusão e contradição na terminologia, o que serviu como munição para a acusação e argumento para os árbitros deferirem o pedido uruguaio, sem maiores preocupaçóes em discutir os problemas ambientais que daí decorrem. No caso dos produtos fitossanitários, a omissäo legislativa do Brasil, ao deixar de internalizar noma a qual se obrigou internacionalmente, é o que fundamentou a decisão. 
Trata-se em verdade de uma normativa advinda de um órgão do MERCOSUL que, pelo que se percebe, não pode ser rediscutida. Sequer se cogita, aliás, a responsabilidade da própria organizaçäo internacional por eventuais danos que possa vir a causar...

Tanto a defesa brasileira como os árbitros perderam a oportunidade de discutir - quer por comodidade, quer por ingenuidade - questões relevantes vinculadas à contraposiçăo e à compatibilização de dois objetivos do Tratado: a liberalização comercial e a proteção ambiental.

\section{2) Protecionismo}

"Protecionismo" corresponde à imposição de direitos aduaneiros ou restrições na importação com o objetivo de, limitando ou impedindo o ingresso de produtos em um o país, proteger indústrias nacionais da concorrência de produtos estrangeiros ${ }^{23}$.

Os dois laudos arbitrais entenderam protetivas as atitudes do Brasil ao agir ou ao se omitit, em desacordo com os dispositivos do Tratado de Assunção, a despeito da legitimidade da preocupação com a proteção ambiental, sobretudo no laudo relativo aos pneumáticos. Quais seriam, pois, os limites entre uma legítima invocação de proteção ambiental e o protecionismo?

Como antes mencionado, deve-se buscar identificar um e outro no caso concreto. Tal se faz por meio da análise de elementos objetivos presentes no caso que, pelo seu conjunto, são capazes de demonstrar a intenção do Estado-membro. Assim o faz, por exemplo, a Comunidade Européia: o Tribunal de Justiça, em Luxemburgo, ora reconhece o ânimo protecionista de um Estado ao editar uma medida, ora entende legítima a invocação à exceção de que trata o art. 30 do Tratado de Roma. Registre-se, por oportuno, que o estágio atual do Mercosul não é comparável com o da Uniăo Européia; os exemplos a seguit, todavia, mostramse pertinentes:

Entendeu a Corte de Luxemburgo protetiva a atitude do Reino da Dinamarca ao editar uma norma limitando - via contingente - a importação de cervejas e refrigerantes de outros Estados-membros, cujo vasilhames nāo se coadunassem com aqueles previamente registrados no órgão dinamarquês competente, para fins de devolução e reaproveitamento do casco, ainda que o próprio importador ou comerciante ficasse responsável pela devolução e reutilização desses vasilhames. A medida, alegadamente tomada em nome da proteção ambiental, observado o sistema de reciclagem vigente no país, era discriminatória e, neste sentido, contrária às disposiçóes do Tratado de Roma. Isto porque os registros de vasilhames advindos de outro Estado-membro eram deliberadamente negados,

${ }_{23}$ Conf. WEIGALL, David, International Relations, London: Arnold, 2002, p. 185; RATTI, Bruno, ob. cit., p. 188. 
mesmo que o comerciante ou importador fosse o responsável pelo recolhimento e reutilização dos vasilhames. A Comissão alegou e o Tribunal acatou o argumento de que a fixação de contingente anual para importação não demonstra que a medida seja propicia para atingir os fins alegadamente desejados pelo Estado dinamarquês ${ }^{24}$. Neste sentido, concluo, a medida a ser tomada para proteger o meio ambiente en detrimento da livre circulação de mercadorias deve se coerente e não arbitrária em relação aos fins a que se destina.

Quanto à exigência de registro e controle de produtos químicos advindos de outro Estado-membro, entendeu o tribunal, afastando-se um pouco da linha da conhecida decisão "Cassis de Dijon" ${ }^{\text {"25 }}$, que não é vedado a um Estado. membro tal procedimento, mesmo que no Estado membro de origem o produto já disponha de autorização para circular. Porém, exige-se para tanto que haja efetiva necessidade de análises técnicas ou químicas ou testes laboratoriais do produto em questão, em se tratando dos mesmos tipos de controle em um e em outro Estado, e que os resultados da análise sejam colocados à disposição do Estado de destino. Isto para evitar custos desnecessários com duplicidade de controles, quando o primeiro deles, efetuado em outro Estado-membro, já basta para verificar as exigências relativas à proteção da saúde ${ }^{26}$.

Não se verificou discriminação arbitrária, pelo estado então atual (1975) da regulamentação comunitária, o controle fitossanitário de produto vegetal advindo de um Estado-membro, com base no art. 36 do Tratado de Roma (atual art. 30). Porém, pode se constituir arbitrário o controle quando os produtos nacionais não säo submetidos a controle equivalente ${ }^{27}$.

Poder-se-ia elencar aqui outros tantos exemplos para delimitar protecionismo de legítima invocação à proteção ambiental e à saúde humana. A idéia é, todavia, incentivar a reflexăo e a discussão. Reflexão e discussão estas, infelizmente, insuficientes nas contra-razóes do rétu e, por via de conseqüência, nos fundamentos da decisão dos laudos do Mercosul em análise. E onde não há discussão, a evolução do processo de integração é ilusória. O sistema de solução de controvérsias adotado pelo Mercosul, descomprometido com o próprio processo de integração que visa defender, à medida em que não há continuidade efetivá, é passível de críticas. A posição do Brasil, quer no âmbito internacional, pelas posiçóes que assume e não cumpre, quer no âmbito interno, pelas contradições legislativas, também é passível de críticas. Os laudos, também passíveis de crítica, apenas ilustram esta realidade. É esta a integração que querenos?

\footnotetext{
${ }^{24}$ Ac. $302 / 86$ de 20.9.1988 (Comissão versus Reino da Dinamarca), TJCE Col. 1988, p. 4607.

${ }_{25}$ Ac. $120 / 78$ de 20.02.1979 (Rewe-Zentraj-AG versus Bundesmonopolverwaltung für Branntwein). TJCE Col. 1979, p. 649.

${ }^{26}$ Ac. $272 / 80$ de 17.12 .1981 (Processo Penal contra Frans-Nederlandse Maatschappil voor Biologische Producten BV), TJCE Col. 1981, p. 3277.

${ }_{27}$ Ac. $4 / 75$ de 8.7.1975 (Rewe Zentralfinanz versus Landwirtschaftskammer Bonn), TJCE Co!. 1975, p. 843).
} 